\title{
Pyloric gland adenoma in the duodenal bulb: case report of a giant laterally spreading tumor treated with endoscopic submucosal dissection
}

A 55-year-old man underwent gastroduodenoscopy because of epigastric pain. Abdominal computed tomography revealed a uniformly enhanced mass $(10 \times 8 \mathrm{~mm})$ within the duodenum, with no enlargement of lymph nodes ( Fig.1). A laterally spreading tumor, with a diameter of about $60 \mathrm{~mm}$, was detected within the duodenal bulb ( Fig.2). The lesion involved the pylorus ring and had a positive lifting sign. Considering the difficulty of endoscopic resection of such a giant lesion in the duodenal bulb, surgical resection was proposed, but the patient refused. Therefore, a standard endoscopic submucosal dissection was performed ( $\downarrow$ Video 1 ).

Grossly, the resected tissue measured $60 \times 50 \mathrm{~mm}$ ( $\mathbf{F i g . 3}$ ). The pathological examination revealed pyloric gland adenoma accompanied by some regional high grade intraepithelial neoplasia ( $\triangleright$ Fig.4). The lateral and vertical margins of the specimen were negative. No complications occurred during the procedure.

A repeat gastroduodenoscopy about 1 year later showed no significant abnormalities in the duodenal bulb ( $\triangleright$ Fig. 5).

Pyloric gland adenoma (PGA) is a rare neoplasm, composed of tightly packed tubules (occasionally cystic dilation) with pyloric gland differentiation, which mainly occurs in the stomach [1]. Since the first description of PGA by Elster in 1976, few PGAs have been documented to originate from the duodenum [2,3] and other extragastric sites; in addition, most reported PGAs have been $<25 \mathrm{~mm}$ [4]. Nowadays, PGA is a recognized precancerous disease, with a reported rate of association with adenocarcinoma ranging from $12 \%$ to $47 \%$ [5]. The risk of developing adenocarcinoma is associated with its size and the presence of high grade dysplasia [4]. Therefore, endoscopic removal of PGA is indicated. In our report, a rare giant duodenal PGA was described and

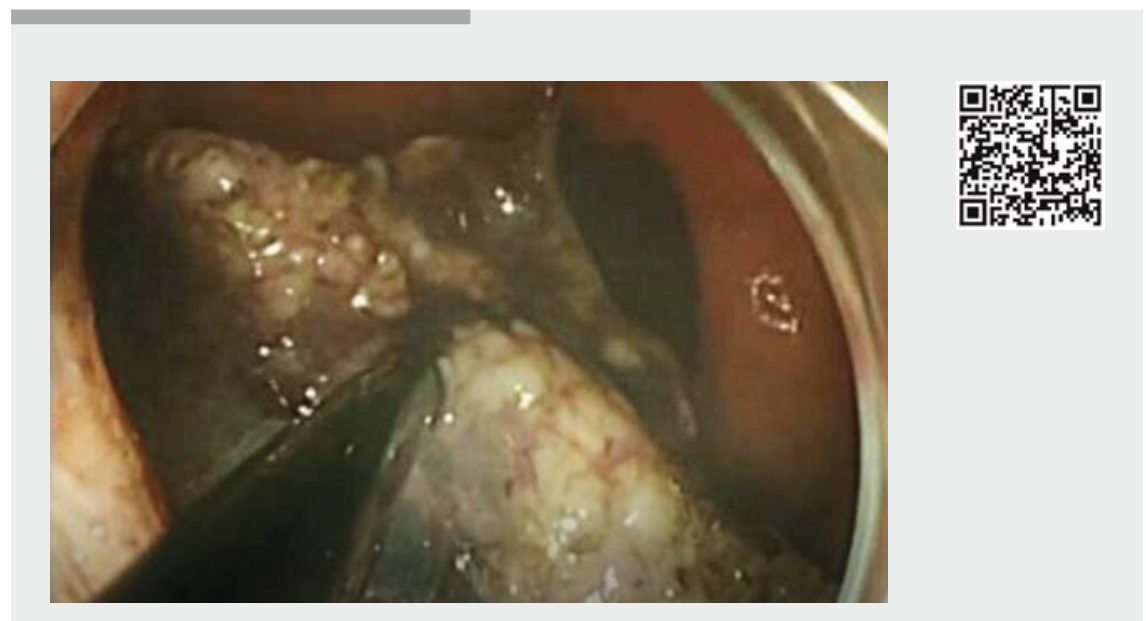

Video 1 Endoscopic submucosal dissection of a large laterally spreading pyloric gland adenoma in the duodenal bulb.

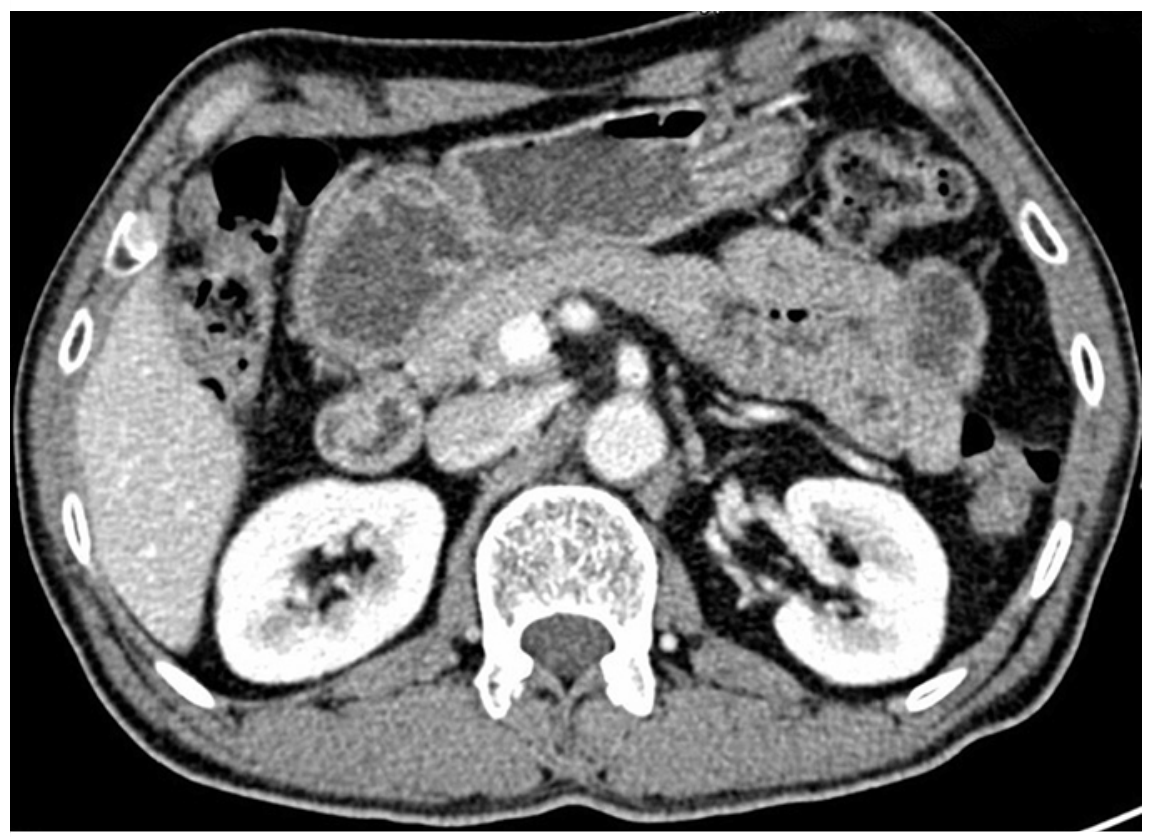

- Fig. 1 Abdominal computed tomography revealed a uniformly enhanced mass within the duodenum, without enlargement of lymph nodes.

successfully treated with endoscopic Endoscopy_UCTN_Code_CCL_1AB_2AZ_3AB submucosal dissection. 


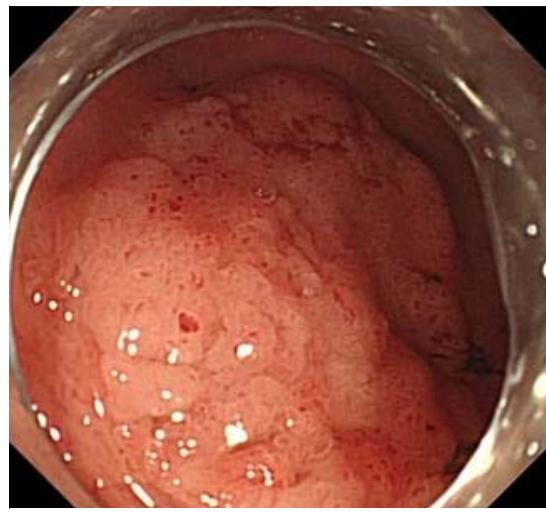

Fig. 2 A laterally spreading tumor in the duodenal bulb.

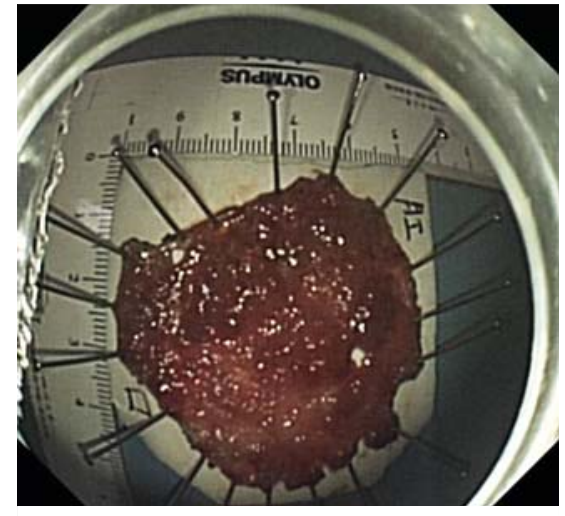

$\checkmark$ Fig. 3 The resected tumor was $60 \times 50 \mathrm{~mm}$ in diameter.

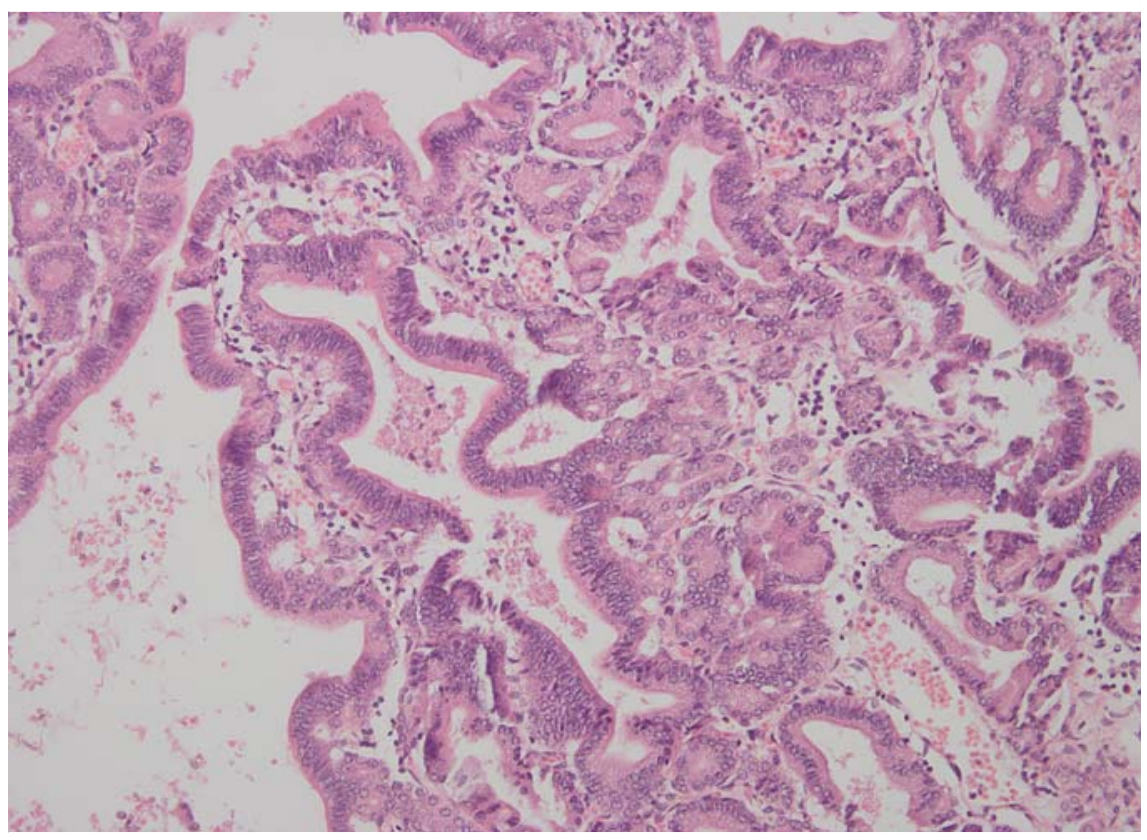

- Fig. 4 Histological examination revealed closely packed pyloric gland-type glands made up of cuboidal to columnar epithelial cells with pale to eosinophilic cytoplasm (hematoxylin and eosin, $\times 200$ ).

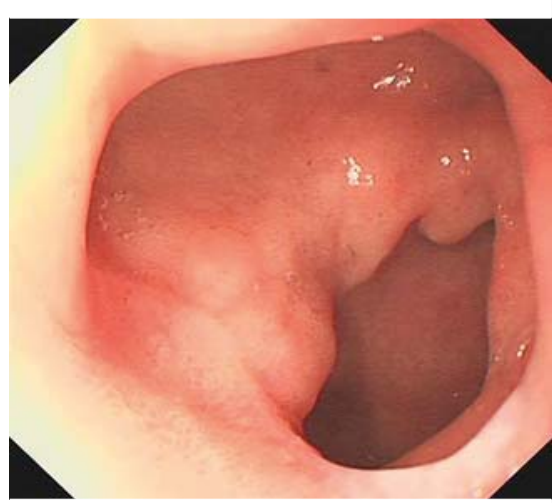

\section{Competing interests}

None

The authors

\section{Qi-Shan Zeng*, Lian-Song Ye*, Chun-Cheng Wu, Jian-Rong Liu, Qiong-Ying Zhang, Shuai Bai, Bing Hu}

Department of Gastroenterology, West China Hospital, Sichuan University, Chengdu, China

Fig. 5 Repeat gastroduodenoscopy 1 year later showed no significant abnormalities in the duodenal bulb.

Corresponding author

\section{Bing Hu, MD}

Department of Gastroenterology, West China Hospital, Sichuan University, No. 37 Guo Xue Xiang, Chengdu, Sichuan, 610041, P.R. China

Fax: +86-28-85423387

hubingnj@163.com

\section{References}

[1] Pezhouh MK, Park JY. Gastric pyloric gland adenoma. Arch Pathol Lab Med 2015; 139: $823-826$

[2] Kushima R, Rüthlein HJ, Stolte M et al. "Pyloric gland-type adenoma" arising in heterotopic gastric mucosa of the duodenum, with dysplastic progression of the gastric type. Virchows Arch 1999; 435 : $452-457$

[3] Poeschl EM, Siebert F, Vieth M et al. Pyloric gland adenoma arising in gastric heterotopia within the duodenal bulb. Endoscopy 2011; 43 (Suppl. 02): E336 - 337

[4] Vieth M, Kushima R, Borchard F et al. Pyloric gland adenoma: a clinico-pathological analysis of 90 cases. Virchows Arch 2003; 442: $317-321$

[5] Vieth M, Kushima R, Mukaisho K et al. Immunohistochemical analysis of pyloric gland adenomas using a series of Mucin 2, Mucin 5AC, Mucin 6, CD10, Ki67 and p53. Virchows Arch 2010; 457: 529-536

\section{Bibliography}

DOI https://doi.org/10.1055/a-0862-0098

Published online: 13.3.2019

Endoscopy 2019; 51: E130-E131

(c) Georg Thieme Verlag KG

Stuttgart · New York

ISSN 0013-726X

\section{ENDOSCOPY E-VIDEOS}

https://eref.thieme.de/e-videos

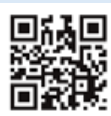

Endoscopy E-Videos is a free access online section, reporting on interesting cases and new techniques in gastroenterological endoscopy. All papers include a high quality video and all contributions are freely accessible online.

This section has its own submission website at https://mc.manuscriptcentral.com/e-videos 